\title{
A review of adjuvant hormonal therapy in breast cancer
}

\author{
Kellie L Jones and Aman U Buzdar ${ }^{1}$
}

Department of Pharmacy, University of Texas M.D. Anderson Cancer Center, 1515 Holcombe Boulevard, Houston, Texas 77030, USA

${ }^{1}$ Department of Breast Medical Oncology, University of Texas M.D. Anderson Cancer Center, 1515 Holcombe Boulevard Unit 424, Houston, Texas 77030, USA

(Requests for offprints should be addressed to Aman U Buzdar; Email: abuzdar@mdanderson.org)

\begin{abstract}
Breast cancer is the most common carcinoma diagnosed in women today excluding non-melanoma skin cancers. It has been well documented that estrogen plays a critical role in its development and is a major target for treatment. For many years, tamoxifen has been the gold standard for adjuvant hormonal therapy in breast cancer patients. With newer products targeting different mechanisms to suppress estrogen production, patients now have many decisions regarding their care. Agents such as luteinizing hormone releasing hormone $(\mathrm{LHRH})$ agonists can suppress ovarian function in premenopausal patients and have been shown to be as effective and even better than chemotherapy (CMF - cyclophosphamide, methotrexate, fluorouracil-containing regimens) in certain patient populations. Tamoxifen continues to be an option as well as toremifene, a similar selective estrogen receptor modulator. With the advent of newer third generation aromatase inhibitors (anastrozole, letrozole and exemestane) toxicities have been documented to be less and in some cases they are more efficacious than the standard, tamoxifen. This article reviews the current data regarding ovarian suppression, ovarian suppression plus tamoxifen, tamoxifen, toremifene, anastrozole, letrozole, and exemestane in the treatment of adjuvant hormonalsensitive breast cancer.
\end{abstract}

Endocrine-Related Cancer (2004) $11391-406$

\section{Introduction}

Breast cancer is the most common cancer diagnosed in women today excluding non-melanoma skin cancers. Due to increased awareness and numerous screening programs, more and more patients are being diagnosed with earlier, more treatable cancers (Weir et al. 2003). In addition, advances in the multidisciplinary approach to treatment (chemo/hormonal therapy, surgery and radiation) have enabled practitioners to treat patients better and to improve outcomes. Hormonal therapy plays an important role in breast cancer and estrogen specifically is targeted in many of the treatments prescribed. It is well established that estrogen plays a critical role in breast cancer. Beatson (1896) discovered this over 100 years ago when he demonstrated a response in a premenopausal woman with breast cancer after an oophorectomy. It was not until approximately 60 years later that estrogen (or the lack of it) was found to be responsible for this clinical effect (Jordan 1999).
The gold standard for the past two decades has been the use of tamoxifen in hormone-sensitive patients (estrogen receptor (ER) positive and/or progesterone receptor (PR) positive). Over the course of 20 years, tamoxifen's indications have broadened from the treatment of metastatic disease to the treatment of early stage breast cancer to even the prevention of disease in high-risk women. Although it is a very effective treatment, tamoxifen does have known side effects such as endometrial cancer, thromboembolic events, and uterine sarcoma (Jaiyesimi et al. 1995, Fisher et al. 1996, Wickerham et al. 2002). Newer agents are now available for this patient population. Toremifene, an analog of tamoxifen, was created under the premise of finding an agent with similar efficacy to tamoxifen but with fewer side effects (Tomas et al. 1995, Wiseman \& Goa 1997, Marttunen et al. 1998). Aromatase inhibitors (AIs) and other modalities such as ovarian suppression with luteinizing hormone releasing factor (LHRH) agonists 
offer different mechanisms to suppress estrogen production and action and these agents have better safety profiles compared with tamoxifen. This article will review each of these hormonal therapies (ovarian suppression, tamoxifen, toremifene, and aromatase inhibitors) in the treatment of hormone-sensitive early breast cancer.

\section{Ovarian ablation as adjuvant therapy}

Ovarian ablation, through surgical oophorectomy or ovarian irradiation, is an effective treatment for premenopausal women with early breast cancer. In a metaanalysis conducted by the Early Breast Cancer Trialists' Collaborative Group (EBCTCG) (1998) women <50 years of age had a significant survival advantage in terms of both disease-free survival (DFS) and overall survival (OS) with ovarian ablation compared with women receiving no adjuvant treatment. These results were comparable with those found in a similar analysis of patients who received adjuvant chemotherapy (EBCTCG 1996). The major disadvantage of oophorectomy or ovarian irradiation for premenopausal patients is the morbidity and mortality associated with these procedures and their irreversibility. Therefore, the LHRH agonists, which produce a medical ovarian ablation, have been developed for the treatment of breast cancer in premenopausal women avoiding the complications associated with surgery and radiation. This therapy allows some patients to maintain their ovarian function after completion of LHRH agonist adjuvant therapy. The most extensively studied LHRH agonist in both the advanced and early breast cancer setting is goserelin acetate (Zoladex), a decapeptide analog of LHRH. Other LHRH agonists (leuprolide (Lupron) and triptorelin (Trilstar)) are available in the USA and are currently undergoing trials in many disease states including breast cancer. Seven phase III trials have been conducted and are described below.

\section{LHRH agonists in early breast cancer (see Table 1 for summary of trials)}

\section{Goserelin as an alternative to chemotherapy}

\section{ZEBRA trial}

To date, the ZEBRA (Zoladex Early Breast Cancer Research Association) trial is the largest adjuvant trial investigating the effect of goserelin in pre/perimenopausal women with early breast cancer $(n=1640)$ (Jonat et al. 2002). In this study, patients were $\leq 50$ years of age, with node-positive, stage II breast cancer who had received no previous systemic treatment. After patients had completed their local therapy (surgery and/or radiotherapy), patients were randomized to receive either goserelin $(3.6 \mathrm{mg}$ s.c. every 28 days for 2 years) or CMF ( 6 cycles) consisting of cyclophosphamide $\left(500 \mathrm{mg} / \mathrm{m}^{2}\right.$ i.v. on days 1 and 8 or $100 \mathrm{mg} / \mathrm{m}^{2}$ orally on days $\left.1-14\right)$, methotrexate $\left(40 \mathrm{mg} / \mathrm{m}^{2}\right.$ i.v. on days 1 and 8$)$ and 5-fluorouracil $\left(600 \mathrm{mg} / \mathrm{m}^{2}\right.$ i.v. on days 1 and 8). Hormone receptor status was not required for entry into the study, but it was left to each center's discretion to enter ER-positive patients. Primary endpoints were DFS and OS. A planned subset analysis of ER status and age was conducted. Return of menstrual function was also assessed. In the first analysis with a median follow-up of 6 years, patient characteristics were well balanced between the groups. In the overall population, DFS was significantly better for CMF compared with goserelin (hazard ratio $(\mathrm{HR})=1.18,95 \%$ confidence interval $(\mathrm{CI})=1.02-1.37, \quad P=0.029)$ unlike $\mathrm{OS}(\mathrm{HR}=1.21$, $95 \% \mathrm{CI}=0.99-1.49, P=0.067)$. When looking only at those patients with ER-positive disease, the results were different. In ER-positive patients only, DFS was demonstrated to be similar with $\mathrm{CMF}$ and with goserelin $(\mathrm{HR}=1.01,95 \% \mathrm{CI}=0.84-1.20, P=0.94)$ while in ERnegative patients goserelin was inferior to $\mathrm{CMF}(\mathrm{HR}=$ $1.76,95 \% \mathrm{CI}=1.27-2.44, P=0.0006)$. Overall survival was similar for CMF and for goserelin in the ER-positive group $(\mathrm{HR}=0.99,95 \% \mathrm{CI}=0.76-1.28, P=0.92)$; however, ER-negative patients did significantly better with $\mathrm{CMF} \quad(\mathrm{HR}=1.77, \quad 95 \% \quad \mathrm{CI}=1.19-2.63, \quad P=0.0043)$ (Jonat et al. 2002).

Updated analyses of the efficacy data were conducted after a median follow-up of 7.3 years and the findings were very similar (Kaufmann et al. 2003). In the overall population, DFS was significantly better for the CMF arm compared with the goserelin arm $(P=0.007)$. In the ER-positive patients, DFS was no better with goserelin compared with CMF $(P=0.597)$ while for ER-negative patients, DFS demonstrated that goserelin was inferior to CMF $(P=0.0001)$. At the time of the updated analysis, $28 \%$ of patients had died. Overall survival for the entire population illustrated no difference with goserelin treatment compared with CMF $(P=0.137)$. ER-positive patients showed non-inferiority of goserelin vs CMF $(P=0.622)$ while ER-negative patients continued to demonstrate significantly better OS with CMF compared with goserelin $(P=0.009)$ thus confirming the lack of efficacy of hormonal treatment for such tumors.

Amenorrhea occurred more rapidly in the goserelin group compared with the CMF arm (Jonat et al. 2002). At 24 weeks, 95\% of patients in the goserelin group had amenorrhea compared with only $59 \%$ in the CMF group. Three years after treatment, menses had returned in the majority of women randomized to goserelin (compared with the only $23 \%$ who remained amenorrheic). Seventyseven percent of patients treated with CMF maintained amenorrhea, suggesting a permanent ovarian ablation. Return of menses did not impact recurrence rate or OS in 
this patient population. This information was based on a subset analysis not originally planned at the beginning of the trial and the authors concluded that this should only be thought of as 'exploratory' data (Jonat et al. 2002).

Side effects in the CMF group were as expected for chemotherapy (see Table 2) and included alopecia, nausea/vomiting and infections. Menopausal symptoms such as vaginal dryness and hot flushes were more prevalent with goserelin compared with CMF. After cessation of treatment, the side effects continued in the CMF group, but were reduced in the goserelin group correlating with the reversible nature of the type of ovarian ablation (Jonat et al. 2002). The side effect profile remained the same across both the original results and the updated analysis (Kaufmann et al. 2003). This trial established goserelin as an effective alternative for the treatment of early breast cancer in premenopausal, nodepositive and ER-positive patients.

\section{Goserelin plus tamoxifen as an alternative to chemotherapy}

\section{ABCSG trial}

The Austrian Breast Cancer Study Group (ABCSG) 05 trial was set up in 1990 to compare DFS and OS among premenopausal women with hormone receptor-positive or -negative, node-positive or -negative early breast cancer (Jakesz et al. 2002). Patients received CMF $\times 6$ cycles (cyclophosphamide $100 \mathrm{mg} / \mathrm{m}^{2}$ orally on days 1-14, methotrexate $40 \mathrm{mg} / \mathrm{m}^{2}$ i.v. and 5-fluorouracil $600 \mathrm{mg} / \mathrm{m}^{2}$ i.v. on days 1 and 8 ) every 28 days or goserelin (3.6 mg SQ every 28 days) for 3 years plus tamoxifen ( $20 \mathrm{mg}$ orally daily) for 5 years. At a median follow-up of 5 years, only $9 \%$ of patients have died from breast cancer, and survival differences between the two treatments were not significant $(P=0.19)$. Nineteen percent of women developed recurrence regardless of hormonal status; however there were significant differences in favor of the group receiving

Table 1 Summary of ovarian suppression trials. DFS in patients with early breast cancer

\begin{tabular}{|c|c|c|c|c|}
\hline $\begin{array}{l}\text { Study } \\
\text { (\# of patients) }\end{array}$ & Treatment & Population & $\begin{array}{c}\text { HR }(95 \% \mathrm{Cl}) \\
\boldsymbol{P} \text { value }\end{array}$ & Results \\
\hline $\begin{array}{l}\text { ZEBRA } \\
(n=1640) \\
\text { (Kaufmann et al. 2003) }\end{array}$ & $\begin{array}{l}\mathrm{G} \times 2 \text { years } \\
\mathrm{CMF}\end{array}$ & $\begin{array}{l}\text { Node }+, \mathrm{ER}(+/-) \text {, } \\
\text { pre/perimenopausal }\end{array}$ & $\begin{array}{c}1.05(0.88-1.24) \\
\text { NS } \\
P=0.597\end{array}$ & $\begin{array}{l}\text { Median } \mathrm{f} / \mathrm{u} \text { of } 7.3 \text { years, } \\
\mathrm{G}=\mathrm{CMF} \text { for DFS in } \\
\text { ER }(+) \text { patients }\end{array}$ \\
\hline $\begin{array}{l}\text { ABCSG } \\
(n=1034) \\
\text { (Jakesz et al. 2002) }\end{array}$ & $\begin{array}{l}\mathrm{G}+\mathrm{T} \times 5 \text { years } \\
\mathrm{CMF}\end{array}$ & $\begin{array}{l}\text { Node }(+/-) \text {, ER }(+/-) \text {, } \\
\text { premenopausal }\end{array}$ & $\begin{array}{c}1.40(1.06-1.87) \\
0.017\end{array}$ & $\begin{array}{l}\mathrm{G}+\mathrm{T} \text { significantly more } \\
\text { effective at } 5 \text { years than } \\
\mathrm{CMF} \text { in } \mathrm{ER}(+) \text { for DFS }\end{array}$ \\
\hline $\begin{array}{l}\text { GROCTA } 02 \\
(n=244) \\
\text { (Boccardo et al. 2000) }\end{array}$ & $\begin{array}{l}\mathrm{G} \times 2 \text { years }+\mathrm{T} 30 \mathrm{mg} \\
\text { daily for } 5 \text { years } \\
\mathrm{CMF}\end{array}$ & $\begin{array}{l}\text { Node }(+/-), \text { ER }+ \text {, } \\
\text { pre/perimenopausal }\end{array}$ & $\begin{array}{c}0.94(0.60-1.47) \\
0.80\end{array}$ & $\begin{array}{l}\mathrm{G}+\mathrm{T} \text { comparable to } \mathrm{CMF} \\
\text { at a median of } 7.4 \text { years } \\
\text { (underpowered for survival) }\end{array}$ \\
\hline $\begin{array}{l}\text { ZIPP } \\
(n=2648) \\
\text { (Rutqvist 1999) }\end{array}$ & $\begin{array}{l}\mathrm{G} \times 2 \text { years } \\
\mathrm{T} \times 2 \text { years } \\
\mathrm{G} \times 2 \text { years }+\mathrm{T} \times 2 \text { years } \\
\text { No further treatment }\end{array}$ & $\begin{array}{l}\text { Node }(+/-) \text {, ER }(+/-) \text {, } \\
\text { premenopausal }\end{array}$ & $\begin{array}{c}0.77(0.66-0.89) \\
<0.001\end{array}$ & $\begin{array}{l}\text { At } 6 \text { years, G vs no further } \\
\text { therapy following standard } \\
\text { therapy shows benefit }\end{array}$ \\
\hline $\begin{array}{l}\text { INT-0101 } \\
(n=1504) \\
\text { (Davidson et al. 1999a,b) }\end{array}$ & $\begin{array}{l}\mathrm{CAF} \text { alone } \\
\mathrm{CAF} \rightarrow \mathrm{G} \times 5 \text { years } \\
\mathrm{CAF} \rightarrow \mathrm{G}+\mathrm{T} \times 5 \text { years }\end{array}$ & $\begin{array}{l}\text { Node + ER +, } \\
\text { premenopausal }\end{array}$ & $\begin{array}{c}0.93(0.76-1.14) \\
0.25 \\
0.73(0.59-0.90) \\
<0.01\end{array}$ & $\begin{array}{l}\text { At } 9 \text { years DFS, } \mathrm{G}+\mathrm{T} \\
\text { compared with } \mathrm{CAF} \text { is } \\
\text { significant }\end{array}$ \\
\hline $\begin{array}{l}\text { IBCSG VIII ER }(+ \text { and }-) \\
(n=1063) \\
(\text { Bianco et al. } 2001)\end{array}$ & $\begin{array}{l}\mathrm{CMF} \\
\mathrm{G} \times 24 \text { months } \\
\mathrm{CMF} \rightarrow \mathrm{G} \times 18 \text { months }\end{array}$ & $\begin{array}{l}\text { Node -, } \\
\text { pre/perimenopausal }\end{array}$ & $\begin{array}{c}1.12(0.74-1.70) \\
0.57 \\
0.73(0.48-1.13) \\
0.16\end{array}$ & $\begin{array}{l}\mathrm{CMF} \rightarrow \mathrm{G} \text { may reduce risk } \\
\text { in } \mathrm{ER}(+) \text { pts compared } \\
\text { with either treatment alone } \\
\text { especially in women } \\
<40 \text { years old }\end{array}$ \\
\hline $\begin{array}{l}\text { MAM-1 GOCSI } \\
(n=466) \\
(\text { Bianco et al. } 2001)\end{array}$ & $\begin{array}{l}\text { CMF alone } \\
A \rightarrow C M F \\
C M F \rightarrow G+T \times 2 \text { years } \\
A \rightarrow C M F \rightarrow G+T \times 2 \text { years }\end{array}$ & $\begin{array}{l}\text { Node }+, \text { ER }(+/-) \text {, } \\
\text { premenopausal }\end{array}$ & $\begin{array}{l}0.71(\mathrm{NR}) \\
0.04\end{array}$ & $\begin{array}{l}\text { Median } \mathrm{f} / \mathrm{u} \text { of } 5 \text { years DFS } \\
\text { was sig. In } \mathrm{G} / \mathrm{T} \text { arms } \\
\text { compared to chemo alone }\end{array}$ \\
\hline
\end{tabular}

DFS, disease free survival; HR, hazard ratio; ZEBRA, Zoladex Early Breast Cancer Research Association; G, goserelin; $\mathrm{T}$, tamoxifen; CMF, cyclophosphamide, methotrexate, fluorouracil; NS, not significant; ABCSG, Austrian Breast and Colorectal Cancer Study Group; GROCTA 02, Gruppo di Recerca in Oncologia Clinica e Terapie Associate; ZIPP, Zoladex in

Premenopausal Patients; INT, Intergroup Trial; $\rightarrow$, followed by; IBCSG, International Breast Cancer Study Group; GOCSI, Gruppo Oncologico Central Sud Isole; A, adriamycin; NR, not reported; f/u, follow-up; pts, patients; CAF, cyclophosphamide, doxorubicin, fluorouracil; sig, significant; chemo, chemotherapy. 
Table 2 Summary of the tolerability results from the ZEBRA trial (Jonat et al. 2002)

\begin{tabular}{|c|c|c|c|c|c|c|}
\hline & \multicolumn{3}{|c|}{ Goserelin $3.6 \mathrm{mg}(n=808)$} & \multicolumn{3}{|c|}{ CMF $(n=802)$} \\
\hline & 24 weeks & 2 years & 3 years & 24 weeks & 2 years & 3 years \\
\hline Nausea/vomiting (\%) & 5.4 & 3.8 & 3.7 & 57.9 & 2.3 & 2.4 \\
\hline Alopecia (\%) & 3.6 & 3.4 & 2.4 & 44.9 & 2.8 & 1.6 \\
\hline Infection (\%) & 4.9 & 1.5 & 3.5 & 13.4 & 3.0 & 3.0 \\
\hline Vaginal dryness (\%) & 25.6 & 25.9 & 9.5 & 15.2 & 13.5 & 14.1 \\
\hline Hot flushes (\%) & 74.6 & 60.4 & 18.6 & 44.6 & 42.4 & 39.6 \\
\hline
\end{tabular}

ZEBRA, Zoladex Early Breast Cancer Research Association; CMF, cyclophosphamide, methotrexate, fluorouracil.

tamoxifen plus LHRH agonists compared with the chemotherapy arm $(P=0.037)$. Recurrence-free survival at 5 years in the hormone receptor-positive subgroup demonstrated that goserelin plus tamoxifen was significantly better than CMF $(P=0.037)$. In addition, local recurrence-free survival also favored goserelin plus tamoxifen in the hormone receptor-positive population $(P=0.015)$. Overall survival was not significantly different between the endocrine arm and the chemotherapy group $(P=0.195)$. Further follow-up is warranted due to the small number of events that have occurred. Hot flushes were the most common side effect reported in the goserelin plus tamoxifen group, but there were more reports of hot flushes, nausea and alopecia in the chemotherapy group compared with the combination arm (Jakesz et al. 2002). The authors concluded that goserelin plus tamoxifen is more effective and better tolerated than CMF as adjuvant therapy in premenopausal women with hormone-sensitive breast cancer.

\section{GROCTA 02 trial}

GROCTA 02 (Italian Breast Cancer Adjuvant ChemoHormone Therapy Cooperative Group Trial) is a randomized, multicenter trial comparing chemotherapy (CMF) with ovarian suppression (either goserelin (3.6 mg SQ every 28 days for 2 years) or ovarian irradiation) plus tamoxifen (20 mg p.o. daily) in premenopausal women for 5 years (Boccardo et al. 2000). A total of 120 patients were randomized to $\mathrm{CMF}$ and 124 patients were randomized to goserelin plus tamoxifen. During the median follow-up of 6.3 years, $37 \%$ of patients relapsed and $18 \%$ of patients died. There were no significant differences in DFS or OS comparing the chemotherapy and endocrine groups (DFS, $P=0.8$; OS, $P=0.3$ ). A separate analysis of patients who received endocrine therapy $(n=119)$ showed that there was no difference in clinical outcome between patients receiving ovarian irradiation $(n=31)$ or goserelin ( $n=82$ ) (38\% vs 33\% relapsed respectively). Six patients had their ovaries removed. Myelosuppression, nausea, vomiting, diarrhea, and alopecia were more common in the CMF group compared with the ovarian ablation plus tamoxifen group while spotting and hot flushes were more common among patients with ovarian ablation plus tamoxifen compared with CMF (Boccardo et al. 2000). This trial demonstrated that the combination of hormonal therapy plus ovarian suppression was safe and effective in ER-positive patients with early breast cancer.

\section{Ovarian suppression in women who maintained ovarian function after chemotherapy}

\section{ZIPP trial}

The ZIPP (Zoladex in Premenopausal Patients) analysis involved a combination of data from randomized trials initiated by four international collaborative groups (Cancer Research Campaign Breast Cancer Trials Group, Stockholm Breast Cancer Study Group, South East Sweden Breast Cancer Group, and Gruppo Interdisciplinaire Valutazione Interventi in Oncologia). These trials ran concurrently with similar protocols. Each center could determine initial treatment (surgery/radiation/chemotherapy) and whether to randomize patients to tamoxifen therapy. Premenopausal patients received primary surgery and standard therapy, which could include chemotherapy (most commonly CMF) and/or radiotherapy. This was followed by randomization to one of four groups: goserelin (3.6 mg SQ every 28 days, for 2 years), tamoxifen ( $20 \mathrm{mg}$ p.o. daily for 2 years), goserelin (3.6 mg SQ every 28 days, for 2 years) plus tamoxifen ( $20 \mathrm{mg}$ p.o. daily for 2 years), or no further endocrine therapy. Results to date have only been published in abstract form. With a median follow-up of 4.3 years, initial results showed that patients who received goserelin in addition to standard chemotherapy compared with no goserelin had a significant decrease in the risk of recurrence $(20 \%$ vs $25 \%$ respectively, $P<0.001)$ (Rutqvist 1999). A benefit in OS was not demonstrated to be statistically significant $(11 \% \quad$ vs $12 \%$ respectively, $P=0.12$ ). The benefit of goserelin was observed irrespective of the use of chemotherapy or tamoxifen treatment. A 5-year update was presented at the meeting of the American Society of Clinical Oncology (ASCO) in 2000 
Endocrine-Related Cancer (2004) 11 391-406

Table 3 Primary outcomes from the INT-0101 trial (Davidson et al. 1999a,b)

\begin{tabular}{lccc}
\hline Event & $\begin{array}{c}\text { CAF } \\
(\%)\end{array}$ & $\begin{array}{c}\text { CAF+goserelin } \\
(\%)\end{array}$ & $\begin{array}{c}\text { CAF+goserelin+tamoxifen } \\
(\%)\end{array}$ \\
\hline $\begin{array}{l}\text { Overall population } \\
\text { 5-year DFS }\end{array}$ & 67 & $\begin{array}{c}70 \\
(P=0.03)(\mathrm{HR}=0.82)\end{array}$ & $\begin{array}{c}77 \\
(P<0.01)(\mathrm{HR}=0.74)\end{array}$ \\
9-year DFS & 57 & 60 & 68 \\
& & $(P=0.25)(\mathrm{HR}=0.93)$ & $(P<0.01)(\mathrm{HR}=0.73)$ \\
5-year OS & 85 & 76 & 86 \\
9-year OS & 70 & 73 & 76 \\
DFS in patients $<40$ years of age & 54 & $(P=0.14)(\mathrm{HR}=0.88)$ & $(P=0.21)(\mathrm{HR}=0.91)$ \\
\hline
\end{tabular}

DFS, disease free survival; OS, overall survival; CAF, cyclophosphamide, doxorubicin, 5-fluorouracil.

which continued to demonstrate significant differences in DFS $(P<0.001)$ but OS was not significant with the goserelin-containing group $(P=0.08)$ (Houghton et al. 2000). Neither abstract documented toxicities or menopausal status changes with regard to treatment received. In this setting, ovarian ablation demonstrated added benefit compared with the other treatment arms. In this study the role of tamoxifen was not adequately addressed.

\section{INT-0101}

INT-0101 was designed to investigate the effect of adjuvant chemohormonal therapy in patients with hormone receptor-positive (estrogen and/or progesterone receptor-positive), node-positive breast tumors (Davidson et al. 1999a,b). Patients were randomized to chemotherapy (CAF - cyclophosphamide $100 \mathrm{mg} / \mathrm{m}^{2}$, orally $\times 14$ days, doxorubicin $30 \mathrm{mg} / \mathrm{m}^{2}$ i.v. on days 1 and 8 , and 5fluorouracil $500 \mathrm{mg} / \mathrm{m}^{2}$ i.v. on days 1 and 8 , for six 28-day cycles), chemotherapy plus goserelin (3.6 mg SQ every 28 days for 5 years), or chemotherapy plus goserelin $(3.6 \mathrm{mg}$ SQ every 28 days for 5 years) plus tamoxifen $(20 \mathrm{mg}$ p.o. daily for 5 years). After 6 years of median follow-up, results showed significant benefit in 5-year DFS only for the triplet arm compared with the other groups. Patients treated with chemotherapy plus goserelin had similar DFS compared with patients receiving chemotherapy alone, thus the value of goserelin alone in this study remains unclear (see Table 3). Overall survival was similar among all three groups (see Table 3 ). In patients $<40$ years of age, the relative benefit in DFS with triplet therapy was particularly marked $(72 \%$ vs $65 \%$ with chemotherapy plus goserelin vs $54 \%$ with chemotherapy alone), although this may be due, in part, to the fact that a high fraction of this subset of women maintained ovarian function in spite of chemotherapy (see Table 3) (Davidson et al. 1999a,b, Kuter 1999). No mention of patients who maintained or lost ovarian function was documented. The INT-0101 trial, which was designed on the basis of the results of the early overview analysis of the EBCTCG showed a benefit for the triplet arm over the chemotherapy alone and chemotherapy plus ovarian ablation.

Davidson and colleagues (2003) presented a 9-year updated analysis at ASCO in 2003. The combination arm of $\mathrm{CAF}+$ goserelin + tamoxifen continued to demonstrate statistically significant reductions in recurrences $(\mathrm{HR}=0.73, \quad P<0.01)$. The chemotherapy + goserelin arm, however, no longer illustrated such benefit $(\mathrm{HR}=$ 0.93, $P=0.25$ ). Overall survival was not significant in either arm. Exploratory retrospective subset analyses were conducted and illustrated a trend of benefit in the following women: those who were $<40$ years of age, premenopausal, those with trends in estradiol levels, and those women who become amenorrheic after CAF. These results were exploratory and continued analysis will identify any benefit based on age, hormone levels, and menopausal status. One limitation of the study was that a chemotherapy + tamoxifen alone arm was not included (which would be considered standard of care) (Davidson et al. 2003).

\section{IBCSG trial}

The IBCSG (International Breast Cancer Study Group) VIII trial randomized 1063 premenopausal women with node-negative, hormone receptor-positive or -negative breast cancer to one of four treatment arms (CastiglioneGertsch et al. 2002). Following surgery, patients were randomized to chemotherapy (CMF $\times 6$ cycles), goserelin alone $(3.6 \times 6$ cycles plus goserelin $(3.6 \mathrm{mg}$ SQ every 28 days for 18 months), or no adjuvant systemic treatment. During the course of this trial, the control arm (no treatment) was dropped due to results from other ongoing trials. Results have recently been published with a median follow-up of 7 years (Castiglione-Gertsch et al. 2003). No difference among the three treatment arms was observed for DFS. Five-year DFS for CMF $\times 6$ was $82 \%(95 \%$ $\mathrm{CI}=78-86 \%)$, while DFS for $\mathrm{CMF} \times 6$ followed by goserelin for 18 months was $87 \%(95 \% \mathrm{CI}=83-91 \%)$ and for goserelin alone it was $79 \%(95 \% \mathrm{CI}=75-84 \%)$. 
No $P$ values were reported based on individual treatment arms; however, the CIs did overlap. $P$ values were reported in the data, but only when comparing combination arms. In patients with ER-positive disease, CMF $\times 6$ or goserelin were equivalent in terms of 5-year DFS (81\%, $95 \% \quad \mathrm{CI}=76-87 \% ; 81 \%, 95 \% \quad \mathrm{CI}=76-87 \%$ respectively). With the sequential administration of $\mathrm{CMF}$ followed by goserelin, 5-year DFS was $86 \%$ with a $95 \%$ CI of $82-91 \%$. Once again no individual $P$ values were reported, but intracomparisons between groups were carried out and $P$ values were reported (CastiglioneGertsch et al. 2003). Cumulative data presented by Castiglione-Gertsch and colleagues (2000) demonstrated that the combination of the three treatment arms resulted in significantly longer DFS compared with the no treatment arm $(77 \%$ vs $60 \%, P=0.02)$. One limitation of the study was that no arms included tamoxifen because at the time of the study conception, it was suggested that tamoxifen would not be beneficial in women less than 50 years of age (EBCTCG 1992). More detailed results and other studies need to be compared to better understand if triplet therapy (chemotherapy + ovarian suppression + other endocrine agents) is better than chemotherapy alone or chemotherapy + tamoxifen.

To help answer these questions, three other complementary trials were initiated by the IBCSG in March 2003 to evaluate the use of chemotherapy, ovarian suppression, and other endocrine therapies (tamoxifen or AIs) as adjuvant therapy. The SOFT trial (Suppression of Ovarian Function Trial) is for women who remain premenopausal after surgery or after the completion of chemotherapy (Francis et al. 2003). Patients are randomized to three treatment arms: tamoxifen $20 \mathrm{mg}$ daily for 5 years, tamoxifen + ovarian suppression with either triptorelin $3.75 \mathrm{mg}$ every 28 days for 5 years or surgical oophorectomy, or lastly exemestane $25 \mathrm{mg}$ daily for 5 years + ovarian suppression. The second study, TEXT (Tamoxifen and Exemestane Trial) is for women who plan to receive ovarian suppression (tripterelin) from the start of their adjuvant therapy and then are randomized to receive either tamoxifen or exemestane concurrently. The last trial, PERCHE (Premenopausal Endocrine Responsive Chemotherapy) randomizes patients to ovarian suppression plus hormonal therapy (tamoxifen or exemestane) or to a triplet arm of chemotherapy, ovarian suppression plus hormonal therapy (tamoxifen or exemestane). The planned target accruals include 3000 patients for the SOFT trial, 1875 patients for the TEXT study, and 1750 patients for the PERCHE trial (Francis et al. 2003).

These trials will help us better to understand treatment options in these populations of patients. In summary, these trials demonstrate ovarian suppression is an effective means of reducing risk of recurrence in ERpositive patients. Results of these studies support the point that ovarian suppression could be utilized as an alternative to chemotherapy in this subset of patients. It should be emphasized that unfortunately many of the trials included ER-negative patients and in many of them tamoxifen was not included. When tamoxifen was added, it was not in the chemotherapy arm and generally it was added in the ovarian suppression arm.

\section{Mam-1 GOCSI trial}

The Mam-1 GOCSI trial began recruitment in 1992. Results have been published in abstract form (Bianco et al. 2001). This study ( $n=446)$ randomized node-positive, premenopausal women to CMF (group A), doxorubicin followed by CMF (group B), CMF followed by goserelin + tamoxifen (group C), and doxorubicin followed by CMF followed by goserelin + tamoxifen (group D). Planned comparisons for rate of relapse were groups $\mathrm{A}+\mathrm{C}$ vs groups $\mathrm{B}+\mathrm{D}$, and groups $\mathrm{A}+\mathrm{B}$ vs groups $\mathrm{C}+\mathrm{D}$. After a median follow-up of 5 years, and adjusting for tumor size, number of lymph nodes and hormone receptor status, there was no difference in DFS between the anthracycline-containing arms vs the non-anthracycline containing arms $(\mathrm{HR}=0.86, P=0.42)$ There was, however, a significant difference between the goserelin plus tamoxifen containing arms vs the chemotherapy alone arms in DFS $(\mathrm{HR}=0.71, P=0.04)$. No differences were demonstrated in OS with the anthracycline-containing arms vs the non-anthracycline containing arms $(\mathrm{HR}=0.79, P=0.31)$ and goserelin plus tamoxifen containing arms vs the chemotherapy alone arms $(\mathrm{HR}=0.86, P=0.52)$ (Bianco et al. 2001). From this limited data, it can be concluded that DFS is superior for patients receiving chemo-endocrine treatment compared with chemotherapy alone in premenopausal patients with breast cancer. No report on OS was published.

\section{Selected SERMS as adjuvant therapy}

\section{Tamoxifen as monotherapy}

In 1986, tamoxifen was the first drug of its kind approved as monotherapy for the treatment of early breast cancer in node-positive, postmenopausal women. Over the course of almost 20 years, this indication has broadened (Jordan 1999). The Nolvadex Adjuvant Trial Organisation (NATO) conducted one of the earliest trials identifying tamoxifen's benefit in delaying recurrence (NATO 1983). Patients were randomized to tamoxifen $10 \mathrm{mg}$ twice daily for 2 years $(n=559)$ vs no further therapy $(n=565)$ after definitive surgery (total mastectomy with either axillary nodal clearance or sampling). The mean follow-up was 21 
months. Significantly fewer events defined as first recurrence of breast cancer, including contralateral disease or death without confirmed recurrence, occurred in the tamoxifen group compared with the no treatment arm $(14.2 \%$ vs $20.5 \%$ respectively, $P=0.01)$. In a subgroup analysis, there was no difference comparing nodal status, menopausal status, or ER positivity between groups (NATO 1983). This was the first of many trials conducted to evaluate the effectiveness of tamoxifen in early breast cancer. At that time, many questions started to surface regarding tamoxifen. Does tamoxifen work in both node-negative and -positive disease? Does tamoxifen work in ER-positive and -negative disease? Does tamoxifen work in both pre- and postmenopausal patients? For how long should you treat with tamoxifen? These questions were answered in subsequent trials.

The Stockholm trial was designed for patients to receive either no adjuvant hormonal therapy or tamoxifen $40 \mathrm{mg}$ /day for 2 years in node-negative, postmenopausal patients (Rutqvist et al. 1992). During the course of the study, the question was raised as to what the appropriate length of tamoxifen therapy should be. This sparked a new trial in which patients who were disease free (DF) at 2 years were randomized to discontinue therapy or continue with tamoxifen for a total of 5 years. After a median follow-up of 7 years, tamoxifen exhibited significant prolongation of DFS compared with the control arm $(P<0.01)$ and fewer deaths $(P=0.02)$. Survival (when analyzing all causes of death) was not significantly better with tamoxifen $(P=0.11)$. As expected based on what we know about ER status and response to therapy with tamoxifen, benefit was documented only in ER-positive patients.

In a further follow-up of 5 years, the event free survival and OS were statistically significant for the 5-year tamoxifen group ( $P=0.03$ and $P=0.009$ respectively). At 10 years, $80 \%$ of the 5 -year group and $74 \%$ of the 2 year group were alive and recurrence free. Benefit was shown regardless of lymph node status, and was identified in ER-positive patients (Rutqvist et al. 1992).

The Scottish trialists group conducted two tamoxifen trials. The first study consisted of patients being randomized to tamoxifen $20 \mathrm{mg}$ /day for 5 years vs tamoxifen $20 \mathrm{mg}$ /day for the treatment until first relapse (control arm) (Breast Cancer Trials Committee \& Scottish Cancer Trials Office 1987). Patients $(n=1312)$ were enrolled with a median follow-up of 47 months. At the time of analysis, 157 patients $(24 \%)$ in the tamoxifen arm and 250 patients $(38 \%)$ in the control arm had developed recurrent disease. The delay in recurrence rate was evident regardless of nodal status. DFS and OS were significantly better in the tamoxifen arm compared with the control arm $(P<0.0001$ and $P=0.002$ respectively).
Another question the investigators wanted to answer was the best duration of therapy. Patients who received tamoxifen for 5 years were then allowed randomization to stop therapy ( $n=169$ ) or continue tamoxifen until relapse $(n=173)$. Fifteen-year follow-up results have now been published (Stewart et al. 2001). The median duration of tamoxifen for the 5-year group was 60 months (range 56205) and in the continuation arm it was 163 months (range 58-205). Overall survival was significantly better in patients taking tamoxifen for 5 years compared with those allocated to continue tamoxifen until recurrence (HR $=0.78, \quad P=0.006)$. Other primary malignancies were identified in this trial across the different treatment arms including endometrial, uterine and ovarian cancers; however, statistical significance of this difference was not achieved. Data in the 5-year arm demonstrated an increased risk of endometrial cancer ( $n=8$ vs 2 in the continuation arm) compared with a decreased risk of contralateral breast cancer $(n=19$ vs $n=2$ in the continuation arm) (Stewart et al. 2001). This trial more clearly identified the benefit of tamoxifen when given for a duration of 5 years.

One of the most important trials conducted was the NSABP B-14 trial which evaluated ER-positive, nodenegative patients with 5 years vs more than 5 years of tamoxifen treatment (Fisher et al. 1996). During the first randomization of tamoxifen vs placebo for 5 years, distant disease-free survival (DDFS) was $76 \%$ with tamoxifen compared with $67 \%$ with placebo $(P<0.0001)$. Overall survival was also significantly improved for the 5-year tamoxifen arm $(P=0.02)$ during the 5-10 years of follow-up. Disease-free survival regardless of age $(<50$ or $>50)$ was statistically significant. Hot flushes, vaginal discharge, irregular menses, deep vein thrombosis, and endometrial cancer occurred more frequently in the tamoxifen arm (Fisher et al. 1993, 1996).

The duration question was tested when patients who had received 5 years of tamoxifen were then randomized to 5 more years of tamoxifen (total 10 years, $n=583$ ) or placebo (total 5 years, $n=570$ ). With a 4-year follow-up, DFS was significantly longer for those who were switched from tamoxifen to placebo - $92 \%$ vs $86 \%$ in those patients who continued tamoxifen for 10 years $(P=0.003)$. Survival rates were not significant at 4 years in the 5-year group compared with the other arm (96\% and $94 \%$ respectively, $P=0.08)$. Disease-free survival, DDFS, and OS were not affected by age. Patients treated for 5 years with tamoxifen experienced fewer recurrences compared with those assigned to the longer treatment arm. Safety profiles were also more favorable in those patients treated for 5 years with tamoxifen compared with those receiving tamoxifen for 
10 years. Side effects were similar to those reported in the earlier part of the trial (Fisher et al. 1993, 1996).

The NSABP B-14 trial was closed early due to the interim analysis identifying no additional benefit of tamoxifen past 5 years. This study reported a $12 \%$ absolute difference in DFS and a $28 \%$ reduction in treatment failure. B-14 confirmed that tamoxifen should be used for 5 years in node-negative, ER-positive patients. The authors stated that tamoxifen should also be used in node-positive patients until further data were available to say otherwise (Fisher et al. 1993, 1996).

EBCTCG (1998) evaluated the largest comparison of tamoxifen vs no tamoxifen in a meta-analysis of 55 trials. Women were identified from trials of tamoxifen for early breast cancer prior to 1990 and were divided into three treatment groups of tamoxifen: (1) about 1 year of tamoxifen, (2) 2 years of tamoxifen, (3) more than 2 years of tamoxifen. Tamoxifen therapy significantly reduced recurrence rates by $18 \%, 25 \%$, and $42 \%$ according to their treatment period (1 year, 2 year, 5 years respectively, $2 P<0.00001)$. Mortality was also significantly reduced by $10 \%$ (1 year), $15 \%$ (2 years), and $22 \%$ (5 years) $(2 P<0.00001)$.

This analysis continued to show the benefit of tamoxifen in women with ER-positive tumors (DFS $=21 \%, 28 \%$, and $50 \%$ for 1 year, 2 years and 5 years respectively) as well as proportional reductions in death of $14 \%, 18 \%$ and $28 \%$ respectively $(P<0.00001)$. The benefit identified was only in ER-positive patients. Benefit from tamoxifen in DFS and OS was no different regardless of lymph node status or age. Contralateral breast cancer reductions were $13 \%, 26 \%$ and $47 \%$ for the different durations of therapy ( 1 year, 2 years and 5 years respectively, $2 P<0.00001)$. The continued analysis of these data every 5 years has directed us to use tamoxifen in ER-positive patients regardless of lymph node or menopausal status (EBCTCG 1998).

The question of duration of therapy was also evaluated in a multicenter trial by the Swedish Breast Cancer Cooperative Group, which addressed 2 years $(n=1801)$ vs 5 years of tamoxifen therapy $(n=1744)$ in postmenopausal patients regardless of nodal status (Swedish Breast Cancer Cooperative Group 1996b). The Stockholm trial previously mentioned was a part of this larger trial and patients contributed information to both trials. Event-free survival and OS were significantly improved with 5 years of therapy compared with only 2 years $(P=0.009$ and $P=0.03$ respectively). The overall absolute reduction in death was $18 \%$ with a 10 -year survival benefit of $6 \%$ in the 5 -year arm. Once again, tamoxifen for 5 years was shown to be beneficial in ERpositive patients regardless of nodal status (Swedish Breast Cancer Cooperative Group 1996a,b). In an update presented at ASCO in 2003, DFS and OS continued to be statistically significant for the group assigned to 5 years of tamoxifen $(P=0.00001$ and $P=0.0002$ respectively) (Nordenskjold et al. 2003). Contralateral breast cancer continued to be significantly reduced (relative risk (RR) $=0.68, P=0.03$ ); however, there was an increased risk of developing endometrial cancer in the 5-year group $(\mathrm{RR}=1.65, P=0.05)$. In this study, patients treated for 5 years with tamoxifen experienced fewer coronary events compared with the patients treated for 2 years with tamoxifen. This may have implications for ongoing trials with AIs.

Other studies are continually evaluating the duration question (Breast Cancer Trials Committee \& Scottish Cancer Trials Office 1987, Current Trials Working Party of the Cancer Research Campaign Breast Cancer Trials Group 1996, Fisher et al. 1996). Two ongoing trials are evaluating tamoxifen for 5 years and longer. The ATLAS (Adjuvant Tamoxifen-Longer Against Shorter) and the aTTom (adjuvant Tamoxifen Treatment offers more) trials plan to recruit over 20000 patients to assist in answering this question (Gray et al. 1997, Davies et al. 1998).

\section{Tamoxifen vs toremifene}

Toremifene (a triphenylethylene antiestrogen) was developed with the premise to demonstrate similar efficacy to tamoxifen but with fewer side effects (Tomas et al. 1995, Wiseman \& Goa 1997, Marttunen et al. 1998). Tamoxifen has been compared with toremifene in postmenopausal patients with node-positive breast cancer in the adjuvant setting (Holli et al. 2000). Patients were randomized to receive tamoxifen $20 \mathrm{mg}$ daily $(n=440)$ or toremifene $40 \mathrm{mg}$ daily $(n=459)$ for 3 years. At the time of the analysis, the median follow-up was 3.4 years. Recurrence rates, OS, and side effect profiles were not significantly different between the groups. Sweating and hot flushes were the most common side effects reported (Holli et al. 2000). The authors concluded that toremifene had similar efficacy and toxicity to tamoxifen in postmenopausal, node-positive early breast cancer patients.

The IBCSG conducted two randomized trials of toremifene $(60 \mathrm{mg} /$ day $)$ compared with tamoxifen ( $20 \mathrm{mg}$ /day) for 5 years in a similar population of patients (Pagani et al. 2003). The IBCSG trial 12-93 and IBCSG trial 14-93 randomized 1035 patients. Seventy-nine percent of patients had ER-positive breast cancer. At 4.9 years of median follow-up, the DFS was $74 \%$ and $70 \%$ for toremifene and tamoxifen respectively. These results were not significantly different and toremifene was considered equivalent to tamoxifen in this setting. These data were presented in abstract form only and no information regarding toxicity was discussed (Pagani et 
al. 2003). Today, we have much more extensive long-term evidence to support tamoxifen's use in the adjuvant setting compared with toremifene. Toremifene is not approved in the adjuvant setting. Of note, the approved dose of toremifene in the metastatic setting is $60 \mathrm{mg}$ daily which is different from what was used in one of the previously stated adjuvant trials.

\section{Tamoxifen plus chemotherapy}

The addition of chemotherapy in the adjuvant setting requires the evaluation of many factors. Intermediate and high-risk patients should receive chemotherapy +/tamoxifen depending on their hormonal receptor status. Other things to consider are age, performance status, and patient preference (Goldhirsch et al. 1998). The EBCTCG has conducted a meta-analysis of randomized trials to evaluate the treatment of breast cancer. In the latest published update, polychemotherapy plus tamoxifen continued to demonstrate a beneficial reduction of recurrence in ER-positive patients regardless of age or menopausal status. Contralateral breast cancer and survival were also improved with combination therapy irrespective of age and menopausal status (EBCTCG 1988). Optimal sequences of treatment modalities have recently been evaluated and patients offered antiestrogen therapy after completion of chemotherapy experienced fewer risks of recurrence compared with concomitant administration of the two modalities (Albain et al. 2002).

\section{Aromatase inhibitors}

AIs are currently being studied extensively in the adjuvant setting. Several major trials are underway evaluating these agents (see Table 4). The earliest Food and Drug Administration (FDA)-approved AI was aminoglutethimide. This first generation AI has been compared with tamoxifen in the adjuvant setting. Although efficacy was exhibited with aminoglutethimide, a lack of survival benefit compared with tamoxifen was observed at an 8year follow up (Jones et al. 1992). Due to its nonspecificity for the aromatase enzyme, aminoglutethimide has numerous side effects and supplemental hydrocortisone must be administered concomitantly. The Austrian Breast and Colorectal Cancer Study Group conducted one combination trial with tamoxifen and aminoglutethimide (Schmid et al. 2003). Patients $(n=2021)$ were randomized to receive either tamoxifen $(40 \mathrm{mg} /$ day for the first 2 years, then $20 \mathrm{mg}$ daily for 3 years) or the combination of tamoxifen (same regimen) plus aminoglutethimide $(500 \mathrm{mg}$ /daily for the first 2 years). At the median follow-up of 5.3 years, DFS was not significantly different between combination therapy and tamoxifen

Table 4 Adjuvant aromatase inhibitor trials currently ongoing (Goss 2001)

\begin{tabular}{|c|c|}
\hline Study & Schema \\
\hline BIG/FEMTA & $\begin{array}{l}\text { 1. } L \text { for } 5 \text { years } \\
\text { 2. } T \text { for } 2 \text { years } \rightarrow L \text { for } 3 \text { years } \\
\text { 3. } L \text { for } 2 \text { years } \rightarrow T \text { for } 3 \text { years } \\
\text { 4. } T \text { for } 5 \text { years }\end{array}$ \\
\hline MA-17 (tamoxifen for 5 years) & $\begin{array}{l}\text { 1. } L \text { for } 5 \text { years } \\
\text { 2. } P \text { for } 5 \text { years }\end{array}$ \\
\hline EXACT trial by ICCG & $\begin{array}{l}\text { 1. } T \text { for } 5 \text { years } \\
\text { 2. } T \text { for } 2-3 \text { years } \rightarrow E \text { for } 2-3 \text { years }\end{array}$ \\
\hline NSABP B-33 (tamoxifen for 5 years) & $\begin{array}{l}\text { 1. } E \text { for } 2 \text { years } \\
\text { 2. } P \text { for } 2 \text { years }\end{array}$ \\
\hline ATAC & $\begin{array}{l}\text { 1. } T \text { for } 5 \text { years } \\
\text { 2. A for } 5 \text { years } \\
\text { 3. } T \text { plus } A \text { for } 5 \text { years }\end{array}$ \\
\hline ARNO trial by ABCSG & $\begin{array}{l}\text { 1. } T \text { for } 5 \text { years } \\
\text { 2. } T \text { for } 2 \text { years } \rightarrow A \text { for } 3 \text { years }\end{array}$ \\
\hline TEAM/USON & $\begin{array}{l}\text { 1. } T \text { for } 5 \text { years } \\
\text { 2. } E \text { for } 5 \text { years }\end{array}$ \\
\hline MA-27 & $\begin{array}{l}\text { 1. E for } 5 \text { years with celecoxib bid } \times 3 \text { years } \\
\text { 2. E for } 5 \text { years with placebo bid } \times 3 \text { years } \\
\text { 3. A for } 5 \text { years with celecoxib bid } \times 3 \text { years } \\
\text { 4. A for } 5 \text { years with placebo bid } \times 3 \text { years }\end{array}$ \\
\hline
\end{tabular}

BIG, Breast International Group; L, letrozole; T, tamoxifen; FEMTA, Femara/tamoxifen; P, placebo; ICCG, International Cancer Collaboration Group; E, exemestane; NSABP, National Surgical Adjuvant Breast and Bowel Project; ATAC, Arimidex, Tamoxifen, Alone or in Combination; A, anastrozole; ABCSG, Austrian Breast Cancer Study Group; $\rightarrow$, followed by; TEAM, Tamoxifen Exemestane Adjuvant Multinational Trial; USON, US Oncology. 
groups $(83.6 \%$ vs $83.7 \%$ respectively, $P=0.89)$. Overall survival was not different either $(91.4 \%$ vs $91.2 \%$ respectively, $P=0.74)$. More patients in the combination arm failed to complete therapy due to side effects (14\%) compared with $5.2 \%$ of the tamoxifen arm $(P=0.0001)$ (Schmid et al. 2003). Today aminoglutethimide is not routinely used in clinical practice.

With newer more specific AIs, efficacy has improved and the number of side effects has decreased. As previously mentioned, many trials are currently underway with AIs in the adjuvant setting (see Table 4). Anastrozole (Arimidex), letrozole (Femara), and exemestane (Aromasin) have all provided data that has helped slowly shift the paradigm of hormonal therapy in the adjuvant setting.

\section{Anastrozole}

Anastrozole is currently FDA approved for first and second line metastatic breast cancer as well as in early breast cancer. This approval in the adjuvant setting was based on the results of the ATAC trial (Arimidex, Tamoxifen Alone or in Combination), which is the largest, single cancer treatment study published to date (Baum et al. 2002). Patients were randomized to receive anastrozole $1 \mathrm{mg}$ daily $(n=3125)$, tamoxifen $20 \mathrm{mg}$ daily $(n=3116)$, or the combination daily $(n=3125)$ for 5 years. This was a randomized, double-blind, multicenter trial in postmenopausal women who had completed primary therapy (surgery and/or chemotherapy) for their invasive breast cancer. Disease-free survival, safety and tolerability were the primary end points. Secondary endpoints included time to recurrence (TTR) and incidence of new contralateral primary breast tumors, distant recurrences, and overall survival.

Analysis of the data was planned after 1056 events. The treatment groups were well-balanced overall, with $84 \%$ of patients with hormone-positive breast cancer and $34 \%$ with node-positive disease. Only $8 \%$ of patients were hormone receptor negative and $8 \%$ of patients had an unknown hormone receptor status. This is important because previous AI trials have been criticized due to large numbers of patients with unknown hormonal status (Nabholtz et al. 2000).

At the time of the first analysis, 1079 events had occurred. The median duration of therapy was 30.7 months with a median follow-up of 33.3 months. Diseasefree survival was significantly greater with anastrozole compared with tamoxifen alone (10.1\% vs $12.1 \%$ ) (HR $0.83, P=0.013)$. The combination arm was not significantly different compared with tamoxifen alone $(12.2 \%$ vs $12.1 \%$ ) (HR 1.02, $P=0.8$ ). No difference in death from breast cancer or other reasons was identified across the treatment groups (see Table 5).
Table 5 Results from the ATAC trial (Baum et al. 2003)

\begin{tabular}{lccc}
\hline & $\begin{array}{c}\text { Anastrozole } \\
(n=3125)\end{array}$ & $\begin{array}{c}\text { Tamoxifen } \\
(n=3116)\end{array}$ & $\begin{array}{c}\text { Combination } \\
\text { therapy } \\
(n=3125)\end{array}$ \\
\hline Disease & $13.2 \%$ & $15.1 \%$ & $15.6 \%$ \\
free survival & $(413)$ & $(472)$ & $(488)$ \\
Hormone & $40.2 \%$ & $38.8 \%$ & $36.5 \%$ \\
reception $(+)$ & $(1258)$ & $(1210)$ & $(1142)$ \\
Contralateral & $0.8 \%$ & $1.2 \%$ & $1.1 \%$ \\
breast cancer & $(25)$ & $(40)$ & $(35)$ \\
\hline
\end{tabular}

Hormone receptor-positive disease yielded the best benefit in terms of DFS and TTR. Disease-free survival was significantly better for anastrozole compared with tamoxifen $(\mathrm{HR}=0.82 ; 95 \% \mathrm{CI}, 0.70-0.96 ; P=0.014)$, as well as when compared with the combination arm of anastrozole and tamoxifen $(\mathrm{HR}=1.03 ; 95 \% \mathrm{CI}, 0.89$ $1.20 ; P=0.8)$. No difference in benefit was identified between the tamoxifen and combination arms. Time to recurrence was longer in the anastrozole group than with tamoxifen and no difference was demonstrated in the tamoxifen alone arm compared with the combination group or in those patients with ER-negative disease. Due to the lack of superiority of the combination arm over tamoxifen in either efficacy or safety, the combination arm was closed after the first analysis. At that time, all of the participants on the combination arm of the trial were informed of the results and it was left to the patients and their physicians to decide which one of the two drugs should be discontinued. Patients on the two single arms of the study (anastrozole or tamoxifen alone) remained on the study without breaking the treatment code.

One of the most revealing results was in the reduction of primary contralateral breast cancers. When compared with tamoxifen, anastrozole demonstrated a 58\% risk reduction (HR $0.42, P=0.0068$ ). No statistically significant difference was found with tamoxifen compared with the combination group $(16 \%$ reduction, $P=0.5)$. These results illustrate anastrozole's superiority over tamoxifen for the treatment of postmenopausal women with early breast cancer.

Side effects are an important primary endpoint due to the known toxicities of tamoxifen. The combination arm did not demonstrate differences in toxicities when compared with tamoxifen; however, anastrozole revealed significant reductions in hot flushes, vaginal discharge, vaginal bleeding, ischemic cerebrovascular events, and endometrial cancer. On the other hand, anastrozole exhibited more musculoskeletal disorders and fractures (see Table 6).

Overall, anastrozole showed better efficacy compared with tamoxifen with a relative risk reduction of $17 \%$ in 
Table 6 Toxicities from ATAC trial (Baum et al. 2003)

\begin{tabular}{lcc}
\hline Side effects & $\begin{array}{c}\text { Anastrozole (\%) vs } \\
\text { Tamoxifen (\%) }\end{array}$ & $\boldsymbol{P}$ value \\
\hline Hot flushes & 34.3 vs 39.7 & $<0.0001$ \\
Vaginal discharge & 2.8 vs 11.4 & $<0.0001$ \\
Vaginal bleeding & 4.5 vs 8.2 & $<0.0001$ \\
ICE & 1 vs 2.1 & $<0.0006$ \\
VTE & 1 vs 1.7 & $<0.2$ \\
Endometrial cancer & 0.1 vs 0.5 & 0.02 \\
Musculoskeletal disorders & 27.8 vs 21.3 & $<0.0001$ \\
Fractures & 5.9 vs 3.7 & $<0.0001$ \\
\hline
\end{tabular}

ICE, ischemic cerebrovascular event; VTE, venous thromboembolic event.

DFS. When evaluating only hormone-positive disease, the relative risk reduction for TTR was $27 \%$ compared with tamoxifen. In addition, the incidence of contralateral cancer was significantly improved with a $58 \%$ reduction with anastrozole vs tamoxifen, and the side effect profile was considerably better with anastrozole (Baum et al. 2002). Concerns regarding fracture risk, changes in lipid profiles, and changes in cognition continue, as we do not know the long-term risks of anastrozole in the adjuvant setting.

At the time of publication, many clinicians were sceptical of the ATAC results with a short median follow-up of 33 months. This led to the formation of a working group by ASCO to address these issues. A report was published in 2002 and then again in 2003 with the updated efficacy data (Winer et al. 2002, 2003a). After careful consideration, the group continued its position on the opinion that only a small number of patients have been followed for 5 years of AI therapy (which is considered the standard length of therapy for tamoxifen). Recommendations were not updated due to the absence of differences in survival or any increased efficacy or toxicity. Anastrozole was recommended in postmenopausal women who have an absolute or relative contraindication to tamoxifen. The 47month updated analysis of the trial has confirmed the initial advantage of anastrozole over tamoxifen; however, additional follow-up of the study will define its impact on survival (Winer et al. 2003b).

More results with longer follow-up data have now been presented and published. The ATAC Trialists group presented data with a 47-month median follow-up (Baum et al. 2003, Klijn \& for the ATAC trialists' group 2003). Anastrozole continued to demonstrate benefit in DFS vs tamoxifen $(\mathrm{HR}=0.82(95 \% \mathrm{CI}=0.70-0.96), P=0.014)$. No difference was identified in the comparison of tamoxifen vs the combination arm. The absolute difference in DFS continued to increase over 4 years from $1.5 \%$ in the intent-to-treat group and $1.7 \%$ in the hormone- positive arm at 3 years. At the 4-year follow-up, the numbers have increased to $2.4 \%$ in the overall intent-totreat group and $2.9 \%$ in the hormone receptor-positive arm (Baum et al. 2003, Klijn \& for the ATAC trialists' group 2003).

In addition to efficacy, further analyses of toxicities have also been presented. Locker and Easterll (2003) illustrated the time course of bone fractures in patients undergoing up to 48 months of treatment with adjuvant anastrozole compared with tamoxifen. At both 31 and 37 months, the risk of fractures was similar with anastrozole $(\mathrm{RR}=1.59$ and 1.60 respectively) indicating no worsening of risk over time. The biggest difference was identified between 18 and 24 months. After 2 years of anastrozole, the fracture rate reaches its peak and starts to plateau (Locker \& Easterll 2003). This is the longest follow-up data published to date regarding these toxicities.

At the 2003 San Antonio Breast Cancer Symposium, Duffy and Greenwood (2003) presented data regarding endometrial cancer rates in patients on the ATAC trial. Standard incidence rates (SIR) were analyzed to compare rates seen with anastrozole with those of an age-matched standard population. Anastrozole rates of endometrial cancer were demonstrated to be lower than tamoxifen $(\mathrm{SIR}=0.73(95 \% \mathrm{CI}=0.15-2.12)$ and $2.68(95 \% \mathrm{CI}=$ 1.34-4.80) respectively). This toxicity profile as well as cognition changes, changes in lipid profiles and fracture risks will continue to be prospectively collected. Quality of life has been evaluated in a predefined subset of patients. Overall, there were no significant differences in quality of life in patients on anastrozole compared with tamoxifen; however, patients treated with anastrozole experienced increased frequency of estrogen deprivation symptoms in the form of vaginal dryness, dyspareunia, and loss of interest in sex (Fallowfield 2002).

Another interesting trial presented by Boccardo et al. in 2003 at the San Antonio Breast Symposium, revealed that anastrozole was superior to tamoxifen in women who were already receiving tamoxifen. They randomized 426 patients to receive either tamoxifen $20 \mathrm{mg}$ daily for 5 years or 2 years of tamoxifen followed by 3 years of anastrozole $1 \mathrm{mg}$ daily. The primary endpoints were disease recurrence, second primary tumor, or death. At the time of the analysis, patients had a median follow-up of 24 months. For those patients switched to anastrozole therapy, relapse rates $(\mathrm{HR}=0.36, P=0.006)$ as well as death rates $(\mathrm{HR}=0.18, P=0.07)$ were reduced. This study showed the increased benefit of adding a sequential aromatase inhibitor after tamoxifen therapy (Boccardo et al. 2003). Even though this is a short follow-up, it does pose the question: should we be switching all of our patients who are on tamoxifen over to anastrozole? The answer to this question has not been fully answered. 


\section{Letrozole}

The most recent publication on letrozole has generated a new thought process in the management of patients with adjuvant hormonal therapy. It is known that extending tamoxifen use to 10 years does not add any benefit in OS, and increases toxicity (Fisher et al. 1996). A randomized trial of letrozole in postmenopausal women after completing 5 years of tamoxifen therapy for early stage breast cancer, better known as the MA-17 trial, was conducted to find out if adding a sequential AI after tamoxifen would increase DFS. The National Cancer Institute of Canada Clinical Trialist Group in a joint effort with the North American Intergroup and the Breast International Group led this study. This was a double-blind, placebocontrolled trial. Patients were randomized to receive letrozole $2.5 \mathrm{mg}$ daily $(n=2593)$ for 5 years or placebo $(n=2594)$ for 5 years. Both arms were initiated after completing 5 years of tamoxifen. Disease-free survival was the primary endpoint and secondary endpoints included OS, quality of life, and safety.

Patients had to have completed at least 4.5-6 years of tamoxifen, be ER-positive or unknown, and not to have discontinued tamoxifen more than 3 months prior to enrollment. Statistical methods included two interim analyses to be conducted after 171 and 342 events. Based on the statistical design, early termination would be considered based on results.

The first analysis was conducted after 207 events with a median follow-up of 2.4 years. The estimated 4-year DFS in the letrozole arm was $93 \%$ compared with $87 \%$ in the placebo arm $(\mathrm{HR}=0.57, P=0.00068)$. Fewer local regional and distant recurrences were identified in the treatment group vs placebo $(2.4 \%$ and $4.1 \%$ respectively) as well as contralateral breast cancer $(0.5 \%$ and $1 \%$ respectively). The 4-year estimated OS was not significantly better for letrozole $(P=0.25)$ compared with placebo.

The toxicity profile was evaluated secondarily and illustrated the letrozole arm having significantly more hot flushes, arthritis, arthralgias, and myalgias compared with the placebo arm $(P=0.05)$. Vaginal bleeding was more common in the placebo group $(P=0.01)$. Trends demonstrating higher rates of newly diagnosed osteoporosis with letrozole compared with placebo were identified $(P=0.07)$. As is the case with anastrozole, more long-term data need to be collected regarding bone toxicities with these agents.

Overall, letrozole was shown to lower the risk of recurrence by $43 \%$ and improve the estimated 4 -year DFS by $6 \%$ and OS by $2 \%$. With these results, letrozole has become the first AI to demonstrate benefit in the extended adjuvant setting beyond early tamoxifen (Goss et al. 2003). Because of these overwhelmingly positive results, the data and safety monitoring committee recommended to stop this trial and make the results public.

By stopping the trial after the initial planned analysis, many questions remain unanswered such as the optimal duration of treatment, long-term toxicity, and its impact on survival. Two editorials published in the same issue of the New England Journal of Medicine addressed some of these concerns.

Bryant and Wolmark (2003) raised concerns regarding trials recently stopped due to early interim analysis. The MA-17 trial did have a strict statistical design formulated to stop the study early; however, was that truly beneficial in answering the clinical questions proposed at the beginning of the trial? The primary aim of the study was to determine DFS and secondarily OS of letrozole administered for 5 years after tamoxifen. This was not accomplished with only a median follow-up of 2.4 years. True benefit in survival will never be known due to the crossover ability given to patients when the results were made public. Bryant's conclusions reiterated a need for a new approach to clinical trials with reinforcement to ensure that trials are not stopped early, leaving important clinical questions unanswered.

Burstein (2003) repeated the same concerns, particularly the short follow-up period, lack of long-term safety information, and limited absolute benefit with letrozole. After early release of these results, investigators from the NSABP B-33 trial (a randomized, placebo-controlled, double-blind trial evaluating the effect of exemestane in postmenopausal breast cancers completing at least 5 years of tamoxifen therapy) have suspended accrual. This study provided important new information that alternate, potentially non cross-resistant endocrine therapies can favorably change the natural history of the disease. Closure of this trial after the initial analysis, however, failed to answer two important questions: first, what should be the optimal duration of treatment with AIs; and secondly what ultimately will be the impact on survival? Many other trials are currently underway evaluating AIs in the adjuvant setting and many of them will likely be modified or terminated based on these results.

\section{Exemestane}

Joining the ranks with the other AIs, exemestane now has published information regarding its use in the adjuvant setting. The Intergroup Exemestane Study evaluated sequential exemestane after tamoxifen or tamoxifen alone (Coombes et al. 2004). This was a phase III randomized, double-blind trial which randomized women to receive tamoxifen $20 \mathrm{mg}$ daily for a total of 5 years $(n=2362)$ or exemestane $25 \mathrm{mg}$ daily for 2 to 3 years sequentially after 2 to 3 years of tamoxifen $(n=2380)$. The primary endpoint was DFS (recurrence, diagnosis of 
a second breast cancer, or death). Secondarily, investigators evaluated OS, incidence of contralateral breast cancer, and tolerability. Estrogen receptor-positive patients or those with unknown hormonal status were eligible. Postmenopausal patients (55 years of age or older with amenorrhea for $>2$ years, or amenorrhea for $>1$ year at diagnosis) and those who had received more than 2 years of tamoxifen but no more than 3 years and 1 month were eligible for randomization. Patients were excluded if they had ER-negative disease, were on hormone replacement therapy within 4 weeks of study enrollment, had severe osteoporosis, other cancers, or if they were taking concomitant anticoagulants or any other form of hormonal therapy. This trial was designed to detect an absolute difference of $3.6 \%$ in DFS at 3 years. A planned interim analysis was to be conducted after 716 events occurred. After the second interim analysis reporting on 358 events, it was decided by the safety and monitoring committee to release the results of the study. The adjusted DFS for exemestane included 144 events compared with the tamoxifen arm with 227 events $(\mathrm{HR}=0.63,95 \% \mathrm{CI}=0.51-0.77, P=0.0001)$.

At 3 years, the DFS was $91.5 \%$ in the exemestane group vs $86.8 \%$ in the tamoxifen group for an absolute benefit of $4.7 \%(\mathrm{HR}=0.68, P<0.001)$. Contralateral breast cancer was also significantly reduced in the exemestane arm compared with tamoxifen $(\mathrm{HR}=0.44$, $95 \% \mathrm{CI}=0.20-0.98, P=0.04)$. Survival at this stage of data collection is not statistically significant as would be expected $(\mathrm{HR}=0.88,95 \% \quad \mathrm{CI}=0.67-1.16, \quad P=0.37)$ with a median follow-up of 30.6 months.

The authors did state that the data with regard to side effects were 'provisional' due to the early release of the efficacy data. Tamoxifen patients experienced more problems with vaginal bleeding $(5.5 \%$ vs $4 \%, P=0.05)$, muscle cramps $(4.4 \%$ vs $2.8 \%, P<0.001)$ and thromboembolic disease $(1.9 \%$ vs $1 \%, P=0.03)$. Exemestane patients were documented to have more arthralgias $(5.4 \%$ vs $3.6 \%, P=0.01)$ and diarrhea $(4.3 \%$ vs $2.3 \%$, $P<0.001)$ compared with tamoxifen.

As demonstrated with other aromatase inhibitors, exemestane did cause more cases of fractures compared with tamoxifen $(7.4 \%$ vs $5.7 \%, P=0.05)$. Visual disturbances, which were not discussed in more detail, were reported more in the exemestane arm $(7.4 \%$ vs $5.7 \%$, $P=0.04)$. The number of cardiovascular events in this trial were high but no explanation as to how this was defined was specified. In this study, $42.6 \%$ of exemestane patients and $39.2 \%$ of tamoxifen patients $(P=0.11)$ fell into this category.

Contralateral breast cancer and DFS were significantly improved with the use of sequential exemestane after 2 to 3 years of tamoxifen therapy. The median follow-up at the time of data release was 30.6 months, so differences in overall survival were not significant. The authors do state that at the time of publication, more than $90 \%$ of patients would have completed their therapy, which could add more significance to this data. There are numerous reasons postulated as to why sequential endocrine therapy works, but no one answer has been identified. These questions are slowly being answered. We know from the ATAC trial that anastrozole is better than tamoxifen in terms of efficacy (Baum et al. 2003). Sequential letrozole after 5 years of tamoxifen has shown superiority in the MA-17 trial (Goss et al. 2003). Anastrozole and exemestane have been shown to further decrease the incidence of recurrences in postmenopausal women. The role of letrozole and exemestane as initial treatment instead of tamoxifen remains to be defined by ongoing trials. Currently, the only AI that is FDAapproved in the adjuvant setting is anastrozole; however, a detailed discussion regarding efficacy, toxicity, and timing of tamoxifen, anastrozole, letrozole, and exemestane should be conducted in all postmenopausal patients faced with the decision of taking adjuvant hormonal therapy.

\section{Conclusions}

The role of hormonal therapy has evolved over the course of 100 years. Once it was identified that estrogen played an important role in breast cancer, new therapies were created to inhibit its production and function. Ovarian ablation is a therapeutic option for premenopausal breast cancer patients. The EBCTCG trial demonstrated that DFS and OS were better in those women who received ovarian ablation (i.e. goserelin) compared with those patients who did not receive any adjuvant treatment. When compared with chemotherapy (CMF-like regimens), ovarian ablation showed equivalency, with a better side effects profile. The reversibility of ovarian function is an important caveat. With LHRH agonists such as goserelin, ovarian function can be reversible and can be offered to those patients who wish to maintain function or have children. With the addition of tamoxifen to ovarian ablation, hormonal manipulation has been shown to be more effective than CMF-containing regimens. Other trials are currently underway to evaluate different LHRH agonists and other hormonal therapy combinations with or without chemotherapy in premenopausal breast cancer patients.

Tamoxifen has been the mainstay of hormonal therapy for many years in early breast cancer. It has proven to be effective but it does have a number of side effects. With the creation of AIs, patients now have another option with better tolerability. The results of the 
ATAC trial provided anastrozole as another alternative to tamoxifen therapy in postmenopausal women. This drug has resulted in reductions in the risk of recurrence and an overall better safety profile than tamoxifen. Recent results of the MA-17 trial have demonstrated a benefit with letrozole used sequentially after 5 years of tamoxifen. The data in the exemestane and anastrozole trials for 2 to 3 years after 2 to 3 years of tamoxifen have demonstrated that changing therapy to an AI instead of completing 5 years of tamoxifen can significantly reduce the risk of recurrence. A number of trials are ongoing which will further define the optimal way to utilize AIs in the adjuvant setting. The world of hormonal therapy continues to evolve and it is prudent to discuss the many different options with our patients as they now have choices regarding endocrine therapy.

\section{Funding}

There is no conflict of interest that would prejudice impartiality or be a potential conflict of interest for the authors. Dr Buzdar has received research grants from Astra Zeneca, Pfizer, and Novartis.

\section{References}

Albain K, Green S \& Ravdin P 2002 Adjuvant chemohormonal therapy for primary breast cancer should be sequential instead of concurrent: initial results from intergroup trial 0100 (SWOG-8814). Proceedings of the American Society of Clinical Oncology 2137.

Baum M, Buzdar AU, Cuzick J, Forbes J, Houghton J, Klijn JGM \& Sahmoud T 2002 Anastrozole alone or in combination with tamoxifen versus tamoxifen alone for adjuvant treatment of postmenopausal women with early breast cancer: first results of the ATAC randomized trial. Lancet 359 2131-2139.

Baum M, Buzdar A, Cuzick J, Forbes J, Houghton J, Howell A \& Sahmoud T 2003 Anastrozole alone or in combination with tamoxifen versus tamoxifen alone for adjuvant treatment of postmenopausal women with early-stage breast cancer: results of the ATAC (Arimidex, Tamoxifen Alone or in Combination) trial efficacy and safety update analyses. Cancer 98 1802-1810.

Beatson J 1896 On the treatment of inoperable cases of carcinoma of the mamma: suggestions for a new method of treatment, with illustrative cases. Lancet 104-107 162-165.

Bianco A, Costanzo R \& Di Lorenzo G 2001 The Mam-1 GOCSI trial: a randomised trial with factorial design of chemoendocrine adjuvant treatment in node-positive $(\mathrm{N}+)$ early breast cancer (EBC). Proceedings of the American Society of Clinical Oncology 2027.

Boccardo F, Rubagotti A, Amoroso D, Mesiti M, Romeo D, Sismondi P, Giai M, Genta F, Pacini P, Distante V, Bolognesi A, Aldrighetii D \& Farris A 2000 Cyclophosphamide, methotrexate, and fluorouracil versus tamoxifen plus ovarian suppression as adjuvant treatment of estrogen receptor-positive pre-/perimenopausal breast cancer patients: results of the Italian Breast Cancer Adjuvant Study Group 02 Randomized Trial. Journal of Clinical Oncology 18 2718-2727.

Boccardo F, Rubagotti A \& Amoroso D 2003 Anastrozole appears to be superior to tamoxifen in women already receiving adjuvant tamoxifen treatment. Breast Cancer Research and Treatment $82 \mathrm{~S} 6$.

Breast Cancer Trials Committee \& Scottish Cancer Trials Office 1987 Adjuvant tamoxifen in the management of operable breast cancer: the Scottish Trial. Report from the Breast Cancer Trials Committee, Scottish Cancer Trials Office (MRC), Edinburgh. Lancet 2 171-175.

Bryant J \& Wolmark N 2003 Letrozole after tamoxifen for breast cancer - what is the price of success? New England Journal of Medicine 349 1855-1857.

Burstein HJ 2003 Beyond tamoxifen - extending endocrine treatment for early-stage breast cancer. New England Journal of Medicine 349 1857-1859.

Castiglione-Gertsch M, Gelber RD, O'Neill A, Coates AS \& Goldhirsch A 2000 Systemic adjuvant treatment for premenopausal node-negative breast cancer. The International Breast Cancer Study Group. European Journal of Cancer 36 549-550.

Castiglione-Gertsch M, O'Neill A \& Gelber RD 2002 Is the addition of adjuvant chemotherapy always necessary in nodenegative (N-) pre/perimenopausal breast cancer patients (pts) who receive goserelin. Proceedings of the American Society of Clinical Oncology 2138.

Castiglione-Gertsch M, O'Neill A, Price KN, Goldhirsch A, Coates AS, Colleoni M, Nasi ML, Bonetti M \& Gelber RD 2003 Adjuvant chemotherapy followed by goserelin versus either modality alone for premenopausal lymph nodenegative breast cancer: a randomized trial. Journal of the National Cancer Institute 95 1833-1846.

Coombes RC, Hall E, Gibson LJ, Paridaens R, Jassem J, Delozier T, Jones SE, Alvarez I, Bertelli G, Ortmann O, Coates AS, Bajetta E, Dodwell D, Coleman RE, Fallowfield LJ, Mickiewicz E, Andersen J, Lonning PE, Cocconi G, Stewart A, Stuart N, Snowdon CF, Carpentieri M, Massimini G \& Bliss JM 2004 A randomized trial of exemestane after two to three years of tamoxifen therapy in postmenopausal women with primary breast cancer. New England Journal of Medicine 350 1081-1092.

Current Trials Working Party of the Cancer Research Campaign Breast Cancer Trials Group 1996 Preliminary results from the cancer research campaign trial evaluating tamoxifen duration in women aged fifty years or older with breast cancer. Current Trials Working Party of the Cancer Research Campaign Breast Cancer Trials Group. Journal of the National Cancer Institute 88 1834-1839.

Davidson N, O'Neill A \& Vukov A 1999a Effect of chemohormonal therapy in premenopausal, node $(+)$, receptor $(+)$ breast cancer: an Eastern Cooperative Oncology Group Phase III Intergroup Trial (E5188, INT-0101). Proceedings of the American Society of Clinical Oncology 1867 . 
Davidson N, O'Neill A \& Vukov A $1999 b$ Effect of chemohormonal therapy in premenopausal, node positive, receptor positive breast cancer: an Eastern Cooperative Oncology Group Phase III Intergroup Trial (E5188, INT-0101). Breast 8 232-233.

Davidson NE, O'Neill A \& Vukov A 2003 Chemohormonal therapy in premenopausal node-positive, receptor-positive breast cancer: An Eastern Cooperative Oncology Group phase III intergroup trial (E5188, INT-0101). Proceedings of the American Society of Clinical Oncology 225.

Davies C, Monoghan H \& Peto R 1998 Early breast cancer: how long should tamoxifen continue? European Journal of Cancer $34 \mathrm{~S} 43$.

Duffy S \& Greenwood M 2003 The endometrial cancer data from the ATAC (Arimidex, Tamoxifen, Alone or in Combination) trial indicates a protective effect of anastrozole (arimidex) upon the endometrium. Breast Cancer Research and Treatment 82 S29.

EBCTCG (Early Breast Cancer Trialists' Collaborative Group) 1988 Effects of adjuvant tamoxifen and of cytotoxic therapy on mortality in early breast cancer. New England Journal of Medicine 319 1681-1692.

EBCTCG (Early Breast Cancer Trialists' Collaborative Group) 1992 Systemic treatment of early breast cancer by hormonal, cytotoxic, or immune therapy. 133 randomised trials involving 31000 recurrences and 24000 deaths among 75000 women. Early Breast Cancer Trialists' Collaborative Group. Lancet 339 1-15.

EBCTCG (Early Breast Cancer Trialists' Collaborative Group) 1996 Ovarian ablation in early breast cancer: overview of the randomised trials. Early Breast Cancer Trialists' Collaborative Group. Lancet 348 1189-1196.

EBCTCG (Early Breast Cancer Trialists' Collaborative Group) 1998 Tamoxifen for early breast cancer: an overview of the randomised trials. Lancet 351 1451-1467.

Fallowfield LJ 2002 Assessing the quality of life (QOL) of postmenopausal (PM) women randomized into the ATAC ('Arimidex', tamoxifen, alone or in combination) adjuvant breast cancer (BC) trial. Proceedings of the American Society of Clinical Oncology 2140.

Fisher B, Costantino J \& Wickerham DL 1993 Adjuvant therapy for node-negative breast cancer: an update of NSABP findings. Proceedings of the American Society of Clinical Oncology 1269.

Fisher B, Dignam J, Bryant J, DeCillis A, Wickerham DL, Wolmark N, Costantino J, Redmond C, Fisher ER, Bowman DM, Deschenes L, Dimitrov NV, Margolese RG, Robidoux A, Shibata H, Terz J, Paterson AH, Feldman MI, Farrar W, Evans J \& Lickley HL 1996 Five versus more than five years of tamoxifen therapy for breast cancer patients with negative lymph nodes and estrogen receptor-positive tumors. Journal of the National Cancer Institute 88 1529-1542.

Francis P, Fleming G \& Nasi ML 2003 Tailored treatment investigations for premenopausal women with endocrine responsive $(\mathrm{ER}+$ and/or $\mathrm{PgR}+)$ breast cancer: the SOFT, TEXT, and PERCHE Trials. Breast 12 (Suppl 1) 104, 544.

Goldhirsch A, Glick J \& Gelber RD 1998 Meeting highlights: International Consensus Panel on the Treatment of Primary
Breast Cancer. Journal of the National Cancer Institute $\mathbf{9 0}$ 1601-1608.

Goss PE 2001 Preliminary data from ongoing adjuvant aromatase inhibitor trials. Clinical Cancer Research 7 4397s-4401s.

Goss PE, Ingle JN, Martino S, Robert NJ, Muss HB, Piccart MJ, Castiglione M, Tu D, Shepherd LE, Pritchard KI, Livingston RB, Davidson NE, Norton L, Perez EA, Abrams JS, Therasse P, Palmer MJ \& Pater JL 2003 A randomized trial of letrozole in postmenopausal women after five years of tamoxifen therapy for early-stage breast cancer. New England Journal of Medicine 349 1793-1802.

Gray R, Milligan K, Padmore L \& Study Group 1997 Tamoxifen: assessment of the balance of benefits and risks for long-term treatment. British Journal of Cancer $\mathbf{7 6} 24$.

Holli K, Valavaara R, Blanco G, Kataja V, Hietanen P, Flander M, Pukkala E \& Joensuu H 2000 Safety and efficacy results of a randomized trial comparing adjuvant toremifene and tamoxifen in postmenopausal patients with node-positive breast cancer. Finnish Breast Cancer Group. Journal of Clinical Oncology 18 3487-3494.

Houghton J, Baum M \& Rutqvist L 2000 The ZIPP trial of adjuvant zoladex in premenopausal patients with early breast cancer: an update at five years. Proceedings of the American Society of Clinical Oncology 1993.

Jaiyesimi IA, Buzdar AU, Decker DA \& Hortobagyi GN 1995 Use of tamoxifen for breast cancer: twenty-eight years later. Journal of Clinical Oncology 13 513-529.

Jakesz R, Hausmaninger H, Kubista E, Gnant M, Menzel C, Bauernhofer T, Seifert M, Haider K, Mlineritsch B, Steindorfer P, Kwasny W, Fridrik M, Steger G, Wette V \& Samonigg H 2002 Randomized adjuvant trial of tamoxifen and goserelin versus cyclophosphamide, methotrexate, and fluorouracil: evidence for the superiority of treatment with endocrine blockade in premenopausal patients with hormoneresponsive breast cancer - Austrian Breast and Colorectal Cancer Study Group Trial 5. Journal of Clinical Oncology $204621-4627$.

Jonat W, Kaufmann M, Sauerbrei W, Blamey R, Cuzick J, Namer M, Fogelman I, de Haes JC, de Matteis A, Stewart A, Eiermann W, Szakolczai I, Palmer M, Schumacher M, Geberth M \& Lisboa B 2002 Goserelin versus cyclophosphamide, methotrexate, and fluorouracil as adjuvant therapy in premenopausal patients with nodepositive breast cancer: The Zoladex Early Breast Cancer Research Association Study. Journal of Clinical Oncology 20 4628-4635.

Jones AL, Powles TJ, Law M, Tidy A, Easton D, Coombes RC, Smith IE, McKinna JA, Nash A \& Ford HT 1992 Adjuvant aminoglutethimide for postmenopausal patients with primary breast cancer: analysis at 8 years. Journal of Clinical Oncology $101547-1552$.

Jordan VC 1999 Tamoxifen: For The Treatment And Prevention Of Breast Cancer. Melville, NY: PRR, Inc.

Kaufmann M, Jonat W, Blamey R, Cuzick J, Namer M, Fogelman I, de Haes JC, Schumacher M \& Sauerbrei W 2003 Survival analyses from the ZEBRA study. Goserelin (Zoladex) versus CMF in premenopausal women with 
node-positive breast cancer. European Journal of Cancer 39 1711-1717.

Klijn JGM and for the ATAC Trialists' Group 2003 The ATAC (Anastrozole, Tamoxifen, Alone or in Combination) trial. An efficacy update, focusing on breast cancer (BC) events, based on median follow-up of 47 months. Proceedings of the American Society of Clinical Oncology 2285.

Kuter I 1999 Breast cancer highlights. Oncologist 4 299-308.

Locker G \& Easterll R 2003 The time course of bone fractures observed in the ATAC (Arimidex, Tamoxifen, Alone or in Combination) trial. Proceedings of the American Society of Clinical Oncology 2225.

Marttunen MB, Hietanen P, Tiitinen A \& Ylikorkala O 1998 Comparison of effects of tamoxifen and toremifene on bone biochemistry and bone mineral density in postmenopausal breast cancer patients. Journal of Clinical Endocrinology and Metabolism 83 1158-1162.

Nabholtz JM, Buzdar A, Pollak M, Harwin W, Burton G, Mangalik A, Steinberg M, Webster A \& von Euler M 2000 Anastrozole is superior to tamoxifen as first-line therapy for advanced breast cancer in postmenopausal women: results of a North American multicenter randomized trial. Arimidex Study Group. Journal of Clinical Oncology 18 3758-3767.

NATO (Nolvadex Adjuvant Trial Organisation) 1983 Controlled trial of tamoxifen as adjuvant agent in management of early breast cancer. Interim analysis at four years by Nolvadex Adjuvant Trial Organisation. Lancet 1 257-261.

Nordenskjold B, Rutqvist L \& Malmstrom P 2003 The Swedish Breast Cancer Group trial of two versus five years of adjuvant tamoxifen: disease recurrence, cause-specific mortality, and second primary malignancies. Proceedings of the American Society of Clinical Oncology 2216.

Pagani O, Gelber S \& Simoncini E 2003 Randomized comparison of adjuvant toremifene (Tor) versus tamoxifen (Tam) for postmenopausal women with node-positive $(\mathrm{N}+)$, estrogen receptor-positive $(\mathrm{ER}+)$ early stage breast cancer. Proceedings of the American Society of Clinical Oncology 2220.

Rutqvist L 1999 Zoladex and tamoxifen as adjuvant therapy in premenopausal breast cancer: a randomised trial by the Cancer Research Campaign (C.R.C.) Breast Cancer Trials Group, the Stockholm Breast Cancer Study Group, the South-East Sweden Breast Cancer Group \& the Gruppo Interdisciplinare Valutazione Interventi in Oncologia (G.I.V.I.O). Proceedings of the American Society of Clinical Oncology 1867.

Rutqvist L, Cedermark B \& Glas U 1992 Randomized trial of adjuvant tamoxifen in node-negative postmenopausal breast cancer. Acta Oncologica 31 265-270.

Rutqvist LE and the Swedish Breast Cancer Cooperative Group $1996 a$ Randomised trial of 2 versus 5 years of adjuvant tamoxifen in post-menopausal early stage breast cancer. Proceedings of the American Society of Clinical Oncology 15126.
Schmid M, Jakesz R, Samonigg H, Kubista E, Gnant M, Menzel C, Seifert M, Haider K, Taucher S, Mlineritsch B, Steindorfer P, Kwasny W, Stierer M, Tausch C, Fridrik M, Wette V, Steger G \& Hausmaninger H 2003 Randomized trial of tamoxifen versus tamoxifen plus aminoglutethimide as adjuvant treatment in postmenopausal breast cancer patients with hormone receptor-positive disease: Austrian Breast and Colorectal Cancer Study Group trial 6. Journal of Clinical Oncology 21 984-990.

Stewart HJ, Prescott R \& Forrest P 2001 Scottish Adjuvant Tamoxifen Trial: a randomized study updated 15 years. Journal of the National Cancer Institute 93 456-462.

Swedish Breast Cancer Cooperative Group 1996b Randomized trial of two versus five years of adjuvant tamoxifen for postmenopausal early stage breast cancer. Journal of the National Cancer Institute 88 1543-1549.

Tomas E, Kauppila A, Blanco G, Apaja-Sarkkinen M \& Laatikainen T 1995 Comparison between the effects of tamoxifen and toremifene on the uterus in postmenopausal breast cancer patients. Gynecologic Oncology 59 261-266.

Weir HK, Thun MJ, Hankey BF, Ries LA, Howe HL, Wingo PA, Jemal A, Ward E, Anderson RN \& Edwards BK 2003 Annual report to the nation on the status of cancer, 1975-2000, featuring the uses of surveillance data for cancer prevention and control. Journal of the National Cancer Institute 95 1276-1299.

Wickerham DL, Fisher B, Wolmark N, Bryant J, Costantino J, Bernstein L \& Runowicz CD 2002 Association of tamoxifen and uterine sarcoma. Journal of Clinical Oncology 20 $2758-2760$.

Winer EP, Hudis C, Burstein HJ, Chlebowski RT, Ingle JN, Edge SB, Mamounas EP, Gralow J, Goldstein LJ, Pritchard KI, Braun S, Cobleigh MA, Langer AS, Perotti J, Powles TJ, Whelan TJ \& Browman GP 2002 American Society of Clinical Oncology technology assessment on the use of aromatase inhibitors as adjuvant therapy for women with hormone receptor-positive breast cancer: status report 2002. Journal of Clinical Oncology 20 3317-3327.

Winer EP, Hudis C, Burstein HJ, Bryant J, Chlebowski RT, Ingle JN, Edge SB, Mamounas EP, Gelber R, Gralow J, Goldstein LJ, Pritchard KI, Braun S, Cobleigh MA, Langer AS, Perotti J, Powles TJ, Whelan TJ \& Browman GP 2003 a American Society of Clinical Oncology Technology Assessment Working Group update: use of aromatase inhibitors in the adjuvant setting. Journal of Clinical Oncology 21 2597-2599.

Winer EP, Hudis C, Burstein HJ, Bryant J, Chlebowski RT, Ingle JN, Edge SB, Mamounas EP, Gelber R, Gralow J, Goldstein LJ, Pritchard KI, Braun S, Cobleigh MA, Langer AS, Perotti J, Powles TJ, Whelan TJ \& Browman GP 2003b American Society of Clinical Oncology Technology Assessment Working Group update: use of aromatase inhibitors in the adjuvant setting. Journal of Clinical Oncology 21 2597-2599.

Wiseman LR \& Goa KL 1997 Toremifene. A review of its pharmacological properties and clinical efficacy in the management of advanced breast cancer. Drugs 54 141-160. 